\title{
Insufficient declines in new HIV infection rates amidst high scores in HIV testing and awareness: 'a game theory simulation'
}

\author{
Perez Nicholas Ochanda ${ }^{1}$ (D) $\cdot$ Richard Ssempala $^{2} \cdot$ Allan Kayongo $^{3} \cdot$ Tonny Odokonyero $^{4}$
}

Received: 17 July 2020 / Accepted: 22 February 2021 / Published online: 23 March 2021

(C) The Author(s) 2021

\begin{abstract}
Aim Substantial progress has been made towards the 90-90-90 global targets; however, the pace at which new infections are declining remains undesirable to meet the UNAIDS 2020 global targets of below 500,000 new infections annually. We discussed the possibility of continued HIV incidence amidst remarkable scores in the 90-90-90 global targets.

Subject and methods A game theory simulation was used to explain micro-level sexual interactions in situations of imperfect information on each partner's HIV status. A non-cooperative sex game tree was constructed following the Harsanyi transformation in two scenarios; scenario one: a player assigns higher subjective probability that the partner is HIV negative; and in scenario two: a player assigns higher subjective probability that the partner is HIV positive. Subjective expected utilities were computed using hypothetical payoffs.

Results Accepting unprotected sex is a pure strategy for both players in scenario 1. Player2 is likely to acquire HIV/AIDS. Accepting protected sex is a mixed strategy equilibrium for both players in scenario 2. Player2 is likely to avoid HIV infection. Conclusion Choice for safe or risky sex is a function of subjective probabilities individuals attach to their partners being infected or uninfected. More efforts towards addressing factors affecting individual probability distributions on riskiness of their sexual partners is required, especially for young women in Sub-Saharan Africa.
\end{abstract}

Keywords HIV transmission · Sexual interactions $\cdot$ Game theory $\cdot$ Behavioural elasticity $\cdot$ Young women

\section{Introduction}

The spread of the HIV pandemic in the twenty-first century has continued with disproportional outcomes compared to

Perez Nicholas Ochanda

ochandaperez@gmail.com; POchanda@idi.co.ug

Richard Ssempala

ssempala25@yahoo.com

Allan Kayongo

allankayongo1@gmail.com; akayongo@npa.ug

Tonny Odokonyero

todokonyero@eprcug.org

1 Research Department, Infectious Diseases Institute, College of Health Sciences Makerere University, Kampala, Uganda

2 SPEED Project, School of Public Health, Makerere University, Kampala, Uganda

3 Policy Research and Innovation Department, National Planning Authority, Kampala, Uganda

4 Economic Policy Research Centre, Kampala, Uganda the efforts dedicated towards fighting the disease. Recent UNAIDS reports show substantial progress towards the 90-90-90 global targets; however, the argument on how fast this progress is enhancing reversal of new infections is a worthwhile subject of research. The UNAIDS estimates revealed that the pace at which new HIV infections are declining remains far from that desired to reach the 2020 global target of fewer than 500,000 new annual infections (UNAIDS 2017). Estimates indicate that since 2016, approximately 1.8 million people were newly infected and HIV incidence declined by a mere $11 \%$ (UNAIDS 2017) among people aged 15 and above.

The present study is motivated by a puzzle as to why new HIV infection rates remain high with unpromising declines despite the progress in HIV testing services and awareness programmes globally. Notably, there are approximately 5000 new HIV infections globally every day across all ages with $64 \%$ of new cases in sub-Saharan Africa (UNAIDS 2017). For this reason, we confine the discussion to the SubSaharan African context. This paper contributes to the existing knowledge on HIV infection dynamics by using a game theory simulation to form a theoretical validation of sexual 
behaviour and rational decision making during sexual interactions among the infected and susceptible individuals.

Game theory is a branch of applied mathematics and micro economics that has been applied in different disciplines with its application in public health most relevant when actions of individuals or groups affect the health outcomes of others. It is concerned with the analysis of strategic interactions among agents, and how they reach optimal decision-making assuming rationality (Brickley et al. 2000; Malhotra 2012; Barough et al. 2012). Whereas some efforts have been made to explain the determinants of sexual behaviour and the spread of HIV (Ahituv et al. 1996; Schroeder and Rojas 2002; Tully et al. 2017), more evidence is still needed to explain the micro-level behavioural-dynamics of the spread of HIV as a function of increased HIV tests and awareness. The present paper builds on previous work by adding the gender dimension in sexual behaviours.

\section{HIV Testing and Choice for Safe Sexual Behaviour}

Kaplan (2008) argued that the choice for safe or risky sex is also a function of an individual's knowledge of their HIV status. Given that risky sex yields a higher utility compared to safer sex ceteris paribus; an individual will behave in such a way that, before an HIV test, the perceived utility from risky sex is outweighed by the disutility from contracting HIV. However, after testing and having knowledge of their status as HIV positive, the perceived utility from risky sex outweighs the disutility of contracting the disease. The ultimate deduction from this reasoning is that, infected people will be more likely to engage in risky sex because it is more worth it to them and there is no longer a significant risk to themselves (Philipson and Posner 1995; Schroeder and Rojas 2002; Kaplan 2008; Folland et al. 2013).

Notwithstanding the current achievements towards the UNAIDS 90-90-90 global targets of ending HIV, these achievements do not resonate with the reversal of the epidemic. There is no compelling evidence linking individual's knowledge of their HIV status to the reduction in new infections. Earlier works by Philipson and Posner (1995) attempted to explain how rational individuals would behave after testing and acquiring knowledge of their HIV status. They argued that as more individuals test HIV positive, the spread of HIV may increase rather than fall due to the diminishing incentive to choose safer sex (Philipson and Posner 1995). This deduction forms the underlying focus of discussion for this paper.

\section{Subject and methods}

We use six key conceptual terms in game theory to describe a metaphoric structure of sexual interactions among infected and susceptible individuals. Players are individuals involved in a sexual interaction and faced with the decision to either have sex or not and to protect or not to protect. We can categorize subjects into infected or uninfected, heterosexual partners or homosexual partners. A player may also be first mover (initiator of sex) or follower (the respondent). Game is a strategic situation chosen by an individual (Turocy and VonStengel 2002). We adopt a non-cooperative sex game for this simulation. Information is the knowledge each player has on the other player at each level of the game. This includes partner's HIV status and history of sexual behaviour. Strategy represents the possible choices of action available to each player at each level of the game given their information or assumptions on the other player (Forgo 2004). For this simulation, the strategies are protected sex (PS) or unprotected sex (US) for initiator and accepting (A) or rejecting (R) for respondent given the maximization problem in the sexual interaction.

Payoff is the maximum possible utility each individual obtains from the game. Players (infected and susceptible individuals) seek to maximize utility given their choice strategy (Folland et al. 2013). In this paper, we argue that an individual's expected utility from sexual interaction is a function of their HIV status. However, due to complexities and the illusionary nature of human relations, this may not always be true. Sexual partners may choose to be irrational and feel better off satisfying their partner's desires by following their choice of strategy (protection or non-protection) due to bounded rationality.

The equilibrium we adopted for this type of sex game is the 'no regret' interpretation of the Nash equilibrium - a situation in a game were no player regrets their choice of strategy after observing the opponent's choice (Bananno 2015). Behavioural-economists argue that Nash equilibrium for interactive behaviours may not be achieved in situations where individuals can alter their strategies subject to certain probabilities attached to their opponent's actions. This is because individuals possess a lower propensity to experiment new strategies, for example, condom use in this case, even when it is the rational thing to do (Mullainathan and Thaler 2000; Kaplan 2008). They end up with non-optimal equilibrium because the opportunity cost of trying a new and safer behavioural strategy is high to them. This justifies why some individuals may continue with risky sexual behaviours even after being diagnosed with HIV.

We argue that individual choices on whether to have or accept protected sex or not is a probabilistic belief. That is, individual choices depend on the level of riskiness they attach to their sexual partners being infected. With the modern-day advancements in medical technologies, the predictability of one's HIV status from their physical presentation has become more impractical. Patients can achieve high viral suppression and become asymptomatic (Jaffar et al. 2008). Thus, in a situation of incomplete and imperfect information on one's sexual behavioural patterns and medical history, individual decisions on sexual behaviours will be based on subjective 
probabilistic judgement of the other partner's HIV status (Philipson and Posner 1995; Auld 2006; Ahituv et al. 1996).

\section{Illustrating the non-cooperative sex game model using the Harsanyi transformation}

The Harsanyi transformation of extensive game forms is extensively discussed in (Bananno 2015; Rasmusen 2007). We use a one-sided incomplete information extensive-form game to illustrate the nature of sexual interaction between two players, to understand how susceptible individuals especially young women in this case, may make irrational choices in situations of uncertainty of their sexual partner's HIV status. Given two players 1 and 2, player2 has incomplete information about the HIV status of playerl but has common knowledge about the game being played. Player1 is aware that it's a sex game between the two and is certain of the payoffs given any strategy choice by player2. In this situation, player2 will form their probabilistic belief about playerl's HIV status by assigning subjective probabilities on playerl's HIV status. For instance, player2 may assign a higher probability of two-thirds (2/3) on player1 being HIV positive (hereafter HIV+) and a lower probability of a third (1/3) on player1 being HIV negative (hereafter HIV-) and vice versa.

We make eight simplifying assumptions for this simulation: (i) There are two players 1 and 2. (ii) Player1 initiates the sex with strategies protected sex (hereafter PS) or unprotected sex (hereafter US) while player2 is a follower and can respond with strategies of either accepting (hereafter A) or rejecting (hereafter R). (iii) Knowledge of HIV status significantly impacts on an individual's (the initiator) choice of sex. For the purpose of this simulation, we assume that player1 knows their status as HIV+ and player2 is not informed about playerl's HIV status. (iv) Utility from US is higher than utility from PS. (v) Player2's choice of response is affected by the level of HIV prevalence information within their community and the sexual behavioural elasticity to HIV prevalence information (Ahituv et al. 1996; Kazianga 2005). (vi) HIV prevalence elasticity is negatively related to social cultural and economic inequalities. That is to say, individuals socially and economically disadvantaged are likely to engage in risky sexual activities even with knowledge of HIV prevalence. (vii) To capture the gender perspective of our simulation, we assume player2 (the follower) is a female and (viii) player2 has almost no incentive to reject any form of sex offer as a strategy, since the only worry is the expected utility from either protected sex or risky sex given their probabilistic belief on the HIV status of the other partner. The last assumption is justified by the aspect of bounded rationality in sexual relationships.

Using hypothetical payoffs, we present this simulation in two scenarios in which player2's probabilistic beliefs differ given their degree of responsiveness to the local HIV prevalence information. The payoffs assigned to players in this paper are built on the notion of rationality during sexual interactions. That is to say, individuals would prefer some form of sex to no sex based on their HIV status. We build on extensive work done by (Schroeder and Rojas 2002; Tully et al. 2017). In scenario 1 (Fig. 1), player2 has a low sexual behavioural elasticity to HIV prevalence information (risk loving); therefore, assigning a higher probability on player1 being HIV-. In scenario 2 (Fig. 2), player2 has a high sexual behavioural elasticity to HIV prevalence information (risk averse) and therefore assigns a higher probability on player1 being HIV+ during the sex game. An extensive form game with cardinal payoffs to both players was constructed and players' subjective expected utilities calculated.

\section{Results}

In scenario 1 (Fig. 1), we model the player's strategy profiles and subjective expected utilities (SEU). Each player's action profile and utility value $(\mathrm{U})$ is given as: player1 $[\mathrm{PS}, \mathrm{A}]=$ $1[\mathrm{PS}, \mathrm{R}]=0[\mathrm{US}, \mathrm{A}]=3[\mathrm{US}, \mathrm{R}]=0$ and payer2 $[\mathrm{PS}, \mathrm{A}]=$ $1[\mathrm{PS}, \mathrm{R}]=0[\mathrm{US}, \mathrm{A}]=2[\mathrm{US}, \mathrm{R}]=0$. The subjective expected utility is derived from the formula: $\mathrm{SEUi}=\mathrm{Pi}(\mathrm{Ui})+(1-$ $\mathrm{Pi})(\mathrm{Ui})$ for $\mathrm{i}=1,2 \ldots \mathrm{i}^{\text {th }}$ Player, where $\mathrm{P}$ is the subjective probability player2 attaches on player1 being HIV positive, $U$ is the Von Neumann-Morgenstern utility that represent players preferences (Colman 2005). In scenario 1, the best strategy for player1 is [US, A] which yield the highest payoff of 3 since US is more pleasurable. The best choice strategy for player2

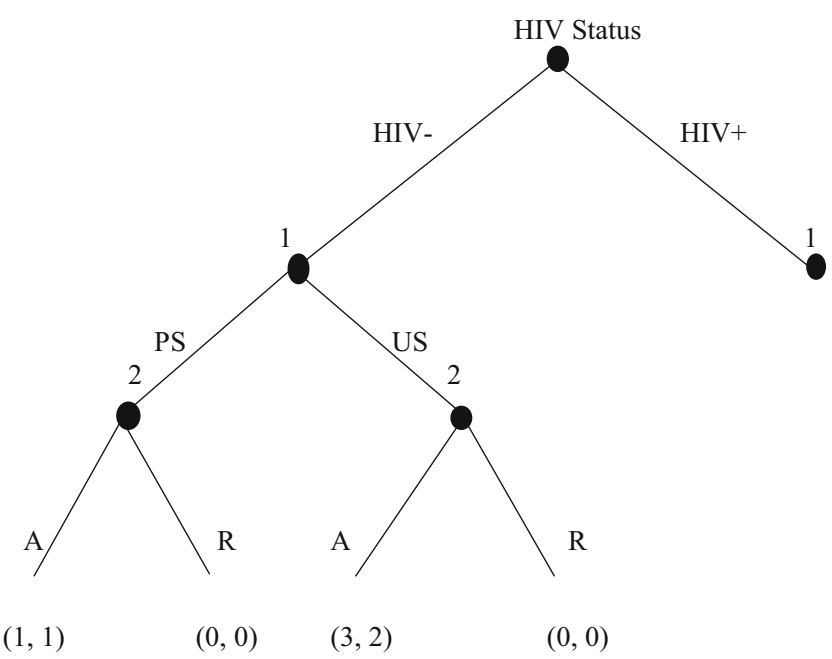

Fig. 1 Player2 assigns a higher subjective probability to player1 being HIV negative. This is a one-sided (left) game representing player1's HIV status as positive. The branches correspond to the choice strategy for each player. Player1 initiates with strategies PS protected sex and US unprotected sex. Player2 follows with strategy $\mathbf{A}$ accept and $\mathbf{R}$ reject. In parenthesis are payoffs to the different choice strategies 


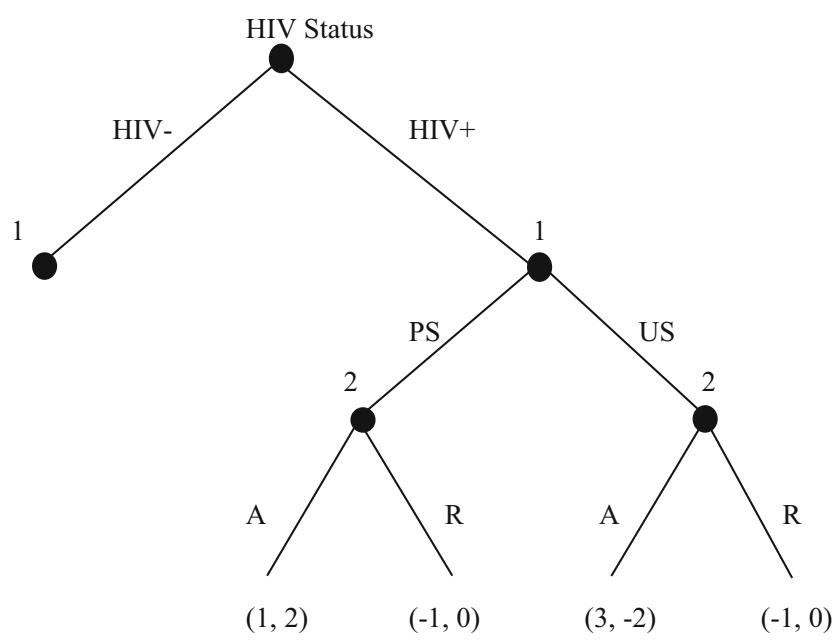

Fig. 2 Player 2 assigns a higher subjective probability to player1 being HIV positive. This is a one-sided (right) game representing player1's HIV status as positive. The branches correspond to the choice strategy for each player. Player1 initiates with strategies PS protected sex and US unprotected sex. Player 2 follows with strategy $\mathbf{A}$ accept and $\mathbf{R}$ reject. In parenthesis are payoffs to the different choice strategies

with a higher subjective probability that player1 is HIV negative is also [US, A] with a payoff of 2 . The strategy [US, A] is the pure strategy equilibrium for both players and maximizes their subjective expected utilities from the game. The SEU for player1 choosing US is computed as $1 / 3(3)+2 / 3(0)=1$, and the SEU for player2 choosing A is computed as $1 / 3(1)+2 /$ $3(2)=1.67$ (Table 1 ). Certainly, player2 is more likely to contract HIV/AIDS given that playerl's best choice for this game would be risky sex (US) and we assumed player1 is HIV positive.
Adopting scenario 2 (Fig. 2), we illustrate a situation where player2 is highly elastic to HIV prevalence information and therefore more cautious about their sexual interactions with both random and non-random partners. The player's strategy action profiles and utility values are given as: player1 [PS, $\mathrm{A}]=1[\mathrm{PS}, \mathrm{R}]=-1[\mathrm{US}, \mathrm{A}]=3[\mathrm{US}, \mathrm{R}]=-2$ and player 2 $[\mathrm{PS}, \mathrm{A}]=2[\mathrm{PS}, \mathrm{R}]=0[\mathrm{US}, \mathrm{A}]=-2[\mathrm{US}, \mathrm{R}]=0$. The best choice strategy for player1 in this case is [US, A] given that the player is HIV+, and thus more likely to offer US. Player2's best strategy choice is [PS, A] with a payoff of 2 . In this scenario (Fig. 2), we get a mixed strategy Nash equilibrium where player1 is forced to play their mixed strategy [PS, A] with a positive but lower payoff of 1 given that player2 chooses to play their pure strategy [PS, A]. This is an optimal equilibrium for player2 but non-optimal for player1 being HIV+. Player2 is highly elastic to local HIV prevalence information, and therefore assigns a higher subjective probability to their sexual partner being HIV+ and prefers to accept sex given that player1 offers protected sex. The SEU for player1 choosing PS is computed as $2 / 3(1)+1 / 3(-1)=0.33$, and that of player 2 choosing $\mathrm{A}$ is computed as $2 / 3(2)+1 / 3(-2)=0.67$. In this case, player 2 is more likely to avoid being infected with HIV/AIDS subject to a higher likelihood of choosing protected sex. Table 1 summarizes individual subjective expected utilities in scenario 1 and 2.

\section{Discussion}

From our simulations of the extensive sex game-form, HIV infection rates would be higher in scenario 1 than in scenario

Table 1 Summary of Individual Subjective Expected Utilities in Scenario 1 and 2

\begin{tabular}{|c|c|c|c|c|c|c|c|c|}
\hline \multirow[t]{3}{*}{ Action Profile } & \multicolumn{4}{|l|}{ Scenario 1} & \multicolumn{4}{|l|}{ Scenario 2} \\
\hline & \multirow{2}{*}{$\begin{array}{l}\text { Player2's subjective prob. } \\
\text { that Player1 is HIV+ }{ }^{\mathrm{f}}\end{array}$} & \multirow[t]{2}{*}{ Pay-off } & \multicolumn{2}{|l|}{$\mathrm{SEU}^{\mathrm{e}}$} & \multirow{2}{*}{$\begin{array}{l}\text { Player2's subjective prob. } \\
\text { that Payer1 is HIV+ }\end{array}$} & \multirow[t]{2}{*}{ Pay-off } & \multicolumn{2}{|l|}{ SEU } \\
\hline & & & Player $1^{\mathrm{g}}$ & Player $2^{\mathrm{h}}$ & & & Player 1 & Player 2 \\
\hline$\left(\mathrm{PS}^{\mathrm{a}}, \mathrm{A}\right)$ & low & $(1,1)$ & 0.33 & 1.67 & high & $(1,2)$ & 0.33 & 0.67 \\
\hline$\left(\mathrm{US}^{\mathrm{b}}, \mathrm{R}\right)$ & low & $(0,0)$ & 2 & 0 & high & $(-1,0)$ & 0.33 & 0 \\
\hline$\left(\mathrm{PS}, \mathrm{R}^{\mathrm{d}}\right)$ & low & $(0,0)$ & 0.67 & 0 & high & $(-1,0)$ & -0.33 & 0 \\
\hline$\left(\mathrm{US}, \mathrm{A}^{\mathrm{c}}\right)$ & low & $(3,2)$ & 1 & 1.33 & high & $(3,-2)$ & 1.67 & -0.67 \\
\hline
\end{tabular}

\footnotetext{
${ }^{\text {a }}$ Protected sex

${ }^{\mathrm{b}}$ Unprotected sex

${ }^{\mathrm{c}}$ Accept

${ }^{\mathrm{d}}$ Reject

${ }^{\text {e }}$ Subjective Expected Utility

${ }^{\mathrm{f}}$ HIV positive

${ }^{g}$ Male

${ }^{\mathrm{h}}$ female
} 
2. This follows that susceptible individuals (player2 in this case) with low sexual behavioural elasticity to any threats of contracting HIV will assign a higher subjective probability to their sexual partners being free from HIV/AIDS, and thus are more willing to accept risky sex offers from the infected individual (player1) unknowingly. This results in higher future incidence rates. This conclusion implies that, as more people get diagnosed with the disease (Player1), they become more fatalistic by offering riskier sex (US) to the susceptible groups, as in Folland et al. (2013). On the other hand, the availability of favourable factors for risk-taking behaviour among susceptible groups, especially young women, increases their vulnerability to accept risky sex.

This discussion incorporates socio-cultural and gender inequalities as major multipliers for new HIV infection rates, especially among women in Africa. Previous studies identified some factors affecting individual behavioural elasticises such as level of education, economic empowerment, cultural drawbacks and gender inequality at all levels (Garcia-Moreno and Watts 2000; Mehra 2013; Udigwe et al. 2014). The pronounced cultural and socio-economic disparities between men and women in Africa have worsened the problem of gender inequality and, consequently, the spread of HIV/AIDS (Garcia-Moreno and Watts 2000). Most women remain dependent on men for economic support, exposing them to male dominance and, consequently, less bargaining power for safe sex during sexual interactions. Most women impulsively incorporate the utility function of their partners into their own, thus making them more willing to engage in risky sex if their sexual partners derive utility from it (Sia et al. 2016; Bouare 2009; Piot et al. 2007; Philipson and Posner 1995). This has made women frequently more vulnerable to the pandemic.

More interestingly, this simulation gives an insight on the global composition of new HIV infections with more infected women than men, specifically in sub-Saharan Africa. In nearly all countries in sub-Saharan Africa and some Caribbean

Table 2 People living with HIV aged 15 years and above from selected African countries in 2017

\begin{tabular}{lll}
\hline Country & Women & Men \\
\hline South Africa & $4,200,000$ & $2,700,000$ \\
Zimbabwe & 740,000 & 510,000 \\
Botswana & 210,000 & 160,000 \\
Angola & 190,000 & 91,000 \\
Kenya & 860,000 & 520,000 \\
Uganda & 750,000 & 490,000 \\
Burundi & 44,000 & 26,000 \\
Cote D'ivoire & 270,000 & 190,000 \\
Democratic Republic of the Congo & 250,000 & 95,000 \\
\hline
\end{tabular}

Compiled from UNAIDS DATA 2018 countries, the majority of people living with HIV (PLHIV) are women mostly aged between 15 and 24 years (Table 2 ). Globally, more than half of PLHIV are women, and $76 \%$ of all these women live in sub-Saharan Africa (UNAIDS 2017). Africa's social structure has generally positioned men as initiators (player1) of sexual interactions and women acting as followers (player2). This has severely compromised women's ability to negotiate safe sex or reject risky sex, thereby compromising their probability distributions on their HIV risk levels in situations of uncertainty.

\section{Conclusion}

In spite of the global achievements in HIV testing and awareness, declines in the incidence rate remain far from expected. This paper discussed the possible continuation of new HIV infections even with higher levels of HIV awareness and testing. We used the game theoretical applications to simulate how the infected and susceptible individuals interact under situations of uncertainty and different levels of risk perception. This discussion focused more on young women being in the susceptible group (player2). From the two scenarios discussed, future HIV incidence is expected to be higher in scenario 1 compared to scenario 2 . In this case, susceptible individuals unknowingly hold a stronger belief that their sexual partner is HIV free and, consequently, their responsiveness to HIV awareness and prevalence information is very low making them more likely to accept risky sex and the reverse is true for scenario 2 .

As young women continue to be exposed to factors associated with risky sexual behaviour and bearing a disproportionate burden of HIV/AIDS, the global goal of reversing and ending the epidemic by 2030 remains ambitious. Strategic policy interventions should focus on improving factors that influence individual responsiveness to HIV risk factors such as education, economic empowerment, domestic violence and gender inequality at all levels. A limitation in our paper is the exclusion of sexual interactions between same-sex partners, which is also a growing concern for HIV in Africa and beyond. This paper contributes to existing knowledge on the sub-optimal outcomes from efforts to reverse new HIV infections globally.

Author's contribution All authors contributed to the writing of the study article. Conception, study design and writing of the manuscript first draft was performed by Perez Nicholas Ochanda; study analysis, review and editing previous versions were performed by Richard Ssempala, Allan Kayongo and Tonny Odokonyero. All authors read and approved the final manuscript.

Funding Open access funding provided by University of Bergen (incl Haukeland University Hospital). 
Data availability Data sharing is not applicable to this article as no new data was created or analysed.

\section{Declarations}

Ethical approval This article does not contain any data collected from human or animal subjects.

Consent to participate This article did obtain informed consent as there was no participation of human subjects.

Consent to publish This article did not obtain consent to publish as there was no participation of human subjects.

Competing interest The authors declare that they have no conflict of interest.

Open Access This article is licensed under a Creative Commons Attribution 4.0 International License, which permits use, sharing, adaptation, distribution and reproduction in any medium or format, as long as you give appropriate credit to the original author(s) and the source, provide a link to the Creative Commons licence, and indicate if changes were made. The images or other third party material in this article are included in the article's Creative Commons licence, unless indicated otherwise in a credit line to the material. If material is not included in the article's Creative Commons licence and your intended use is not permitted by statutory regulation or exceeds the permitted use, you will need to obtain permission directly from the copyright holder. To view a copy of this licence, visit http://creativecommons.org/licenses/by/4.0/.

\section{References}

Ahituv A, Hotz J, Philipson T (1996) The responsiveness of the demand for condoms to the local prevalence of AIDS. J Hum Resour 31(4): 869-897

Auld MC (2006) Estimating behavioural responses to the AIDS epidemic. BE J Econ Anal Poli 5(1):1-29. https://doi.org/10.1515/15380645.1235

Bananno G (2015) Game theory. Davis: University of California. http:// www.econ.ucdavis.edu/faculty/bonanno/

Barough AS, Shoubi MV, Skardi MJ (2012) Application of game theory approach in solving the construction project conflicts. Procedia Soc Behav Sci 58:1586-1593. https://doi.org/10.1016/j.sbspro.2012.09. 1145

Bouare O (2009) Modelling contextual determinants of HIV/AIDS prevalence in South Africa to Infrom policy. Afr J Reprod Health 13(3): $53-70$

Brickley J, Smith CW, Zimmerman JL (2000) An introduction to game theory and business strategy. J Appl Corp Finance 13(2). http:// www.researchgate.net/publication/46540815

Colman AM (2005) Game theory. In: B. Everitt and D. Howell D (Eds). Encyclopedia Stat Behav Sci 2:688-694
Folland S, Goodman AC, Stano M (2013) The economics of health and health care, 7th edn. Pearson, Upper Saddle River

Forgo F (2004) John Von Neumann's contribution to modern game theory. Acta Oeconomica 54(1):73-84. https://doi.org/10.1556/ AOecon.54.2004./.5

Garcia-Moreno C, Watts C (2000) Violence against women: its important for HIV/AIDS. AIDS 14(suppl.3):S253-S265

Jaffar S, Birungi J, Grosskurth H, Amuron B, Namara G, Nabiryo C, Coutinho A (2008) Use of WHO clinincal stage for assessing patient eligibility to antiretroviral therapy in a routine health service setting in Jinja, Uganda. AIDS Res Ther 5. https://doi.org/10.1186/17426405-5-4

Kaplan J (2008) Economic rationality and explaining human behaviour: an adaptionionist program. Int J Interdiscip Soc Sci 3(1833-1882): 79-74 http://www.Social/Sciences-Journal.com

Kazianga H (2005) HIV/AIDS prevalence and the Demand for safe sexual behaviour: Evidence from West Africa. Columbia University. http://www.hkazianga.org/Ppapers/KaziangaHIV Ver3.pdf Accessed February 2005

Malhotra VM (2012) Role of game theory in public health. Online J Health Allied Sci 11(2):2 http://www.ojhas.org/issue42/2012-2-1. htm

Mehra D (2013) Sexual behaviour among Ugandan University students: A gender perspective. Lund University, Department of Clinical Sciences. https://lup.lub.lu.se/record/4064578

Mullainathan S, Thaler R (2000) Behavioural Economics. NBER Working Paper 7948:1094-99. Pergamon, Oxford. http://www. nber.org/papers/w7948

Philipson TJ, Posner RA (1995) The microeconomics of the AIDS epidemics in Africa. Popul Dev Rev 21(4):835-848. https://doi.org/10. 2307/2137776

Piot P, Greener R, Russell S (2007) Squaring the circle: AIDS, poverty and human development. PLOS Med 4(10). https://doi.org/10.1371/ journal.pmed.0040314

Rasmusen E (2007) Law and Game Theory. http://www.rasmusen.org

Schroeder KD, Rojas FG (2002) A game theoretical analysis of sexually transmitted disease epidemics. Ration Soc 14. https://doi.org/10. $1177 / 1043463102014003$

Sia D, Onadja Y, Hajizadeh M (2016) What explains gender inequalities in HIV/AIDS prevalence in Sub-Saharan Africa? Evidence from demographic and health surveys. BMC Public Health 16(1136). https://doi.org/10.1186/s12889-016-3783

Tully S, Cojocaru M, Bauch CT (2017) Multiplayer game and HIV transmission via casual encounters. Math Biosci Eng 14(2):359-376. https://doi.org/10.3934/mbe.2017023

Turocy TL, Von-Stengel B (2002) Game theory. Encyclopedia of information systems, vol 2. Elsevier, San Diego, pp 403-420

Udigwe I, Adogu P, Nwabueze A, Adinma E, Ubajaka C, Onwasigwe C (2014) Factors influencing sexual behavior among female adolescents in Onitsha, Nigeria. Open J Obstet Gynecol 4:987-995. https://doi.org/10.4236/ojog.2014.416139

UNAIDS (2017) 2017 Estimates. Joint United Nations Programme on HIV/AIDS, Geneva

Publisher's note Springer Nature remains neutral with regard to jurisdictional claims in published maps and institutional affiliations. 